\title{
CAN COMPENSATORY GROWTH MITIGATE A FEEDING RESTRICTION IN GROWING LAMBS?
}

\author{
Santiago Luzardo ${ }^{1^{*}}$, Juan Clariget ${ }^{2}$, y Georgget Banchero ${ }^{2}$ \\ ${ }^{1}$ Programa Nacional de Producción de Carne y Lana, Instituto Nacional de Investigación Agropecuaria, \\ Ruta 5, km. 386, Tacuarembó, Uruguay. \\ ${ }^{2}$ Programa Nacional de Producción de Carne y Lana, Instituto Nacional de Investigación Agropecuaria, \\ Ruta 50, km. 11, Colonia, Uruguay. \\ * Corresponding author E-mail: sluzardo@inia.org.uy
}

\begin{abstract}
The aim of the study was to evaluate compensatory growth in lambs under semi-extensive growing conditions utilizing pasture haylage from Lotus uliginosus cv. E-Tanin as the main feed resource. Single $(n=36)$ and twin-born $(n=35)$ crossed Polwarth $x$ Finnish Landrace lambs were assigned to three feeding treatments (restriction period) to achieve: low weight gain (LWG) less than $30 \mathrm{~g} \mathrm{a}^{-1} \mathrm{~d}^{-1}$, medium weight gain (MWG) $\sim 60 \mathrm{~g} \mathrm{a}^{-1} \mathrm{~d}^{-1}$; and high weight gain (HWG) $\left(\sim 90 \mathrm{~g} \mathrm{a}^{-1} \mathrm{~d}^{-1}\right.$ for 82 days. Lambs were offered pasture haylage at LWG, haylage plus corn at MWG, and haylage plus corn and soybean meal at HWG, restricted at 2.5 to $3 \%$ of BW. Afterwards, lambs were individually penned and fed ad libitum for 82 days (refeeding phase). Live weight and feed intake (FI) were recorded during the experimental period, and average daily gain (ADG) and feed conversion ratio (FCR) were estimated. Ribeye area (REA) and fat depth (FAT) were measured in the refeeding phase. Both ADG and FI were significantly different $(P<0.05)$ among treatments $(H W G>$ MWG $>$ LWG) in the feeding restriction period. FCR did not differ $(P>0.05)$ between MWG and HWG but were lower $(P<0.05)$ than LWG. No differences $(P>0.05)$ were found in ADG between single and twin-born lambs during the refeeding period. Initial and final REA was greater $(P<0.05)$ in MWG and HWG than LWG. Even though haylage is a cheap feed alternative in semi-extensive production systems, it does not enable a full compensatory growth of LWG and MWG lambs.
\end{abstract}

Key words: lamb performance, compensatory growth, feed intake, feed conversion ratio.

\section{INTRODUCTION}

Livestock extensive production systems in Uruguay are subject to some extent, to nutritional restriction as a consequence of low quality in summer (Berretta et al., 2000) or availability in winter (Bermúdez and Ayala, 2005) of native grassland. Under extensive conditions, wool type lambs are usually weaned in summer with 4 to 5-month-old facing important nutrition-related challenges during early post-weaning. First, they are offered a poor-quality diet; and secondly, they must cope with parasites, mainly Haemonchus contortus (Castells et al., 2011). Therefore, these lambs usually have little daily weight gain during summer and early fall. A well-known mechanism used to minimize this negative effect is the use of compensatory growth rate, with pastures as main nutrition resource. Haylage is an inexpensive alternative to conserve high quality forage from spring and use it throughout the year when feed resources are scarse in semi-extensive livestock conditions. In our conditions, it could have an additional benefit that haylage can transfer cleanparasites-pastures from spring to summer.

Compensatory growth or catch-up growth are

Received: 18 June 2019. Accepted: 10 July 2019. 
terms used as synonyms to describe the faster than optimal growth that occurs following a period of dietary restriction in the development of many animals (Hector and Nakagawa, 2012). Compensatory growth enables either complete or partial compensation depending on the persistence of the increased growth rate, although there may be no increase in growth rate and hence no compensation. Age at restriction, the severity and duration of the restriction are three major factors contributing to the variation in compensatory growth response of animals (Ryan, 1990; Mitchell, 2009). Several studies have reported some mechanisms that would be associated with compensatory growth, such as feed intake (Graham and Searle, 1979; Hornick et al., 1998; Mc Gregor et al., 2012), growth efficiency (Ryan, 1990; Connor et al., 2010; Keogh et al., 2015a), maintenance energy requirements (Fox et al., 1972; Butler-Hogg and Tulloh, 1982; Sainz et al., 1995) and tissue deposition patterns (Levy et al., 1971; Keogh et al., 2015b).

The objective of the present study was to evaluate animal performance, feed intake and feed conversion ratio during a nutritional restriction period (summer) and ad libitum refeeding phase (fall) in lambs under semi-extensive conditions.

\section{MATERIALS AND METHODS}

\section{Experimental treatments and lamb management}

The experiment was carried out at the Experimental Unit "La Estanzuela" of INIA, Uruguay $\left(34^{\circ} 20^{\prime} \mathrm{S}, 57^{\circ} 41^{\prime} \mathrm{W}\right)$ in summer-fall of 2018. The experimental procedures were approved by the Committee for Animal Ethics of INIA, Uruguay, number 2016.48. After weaning at an average age of 132 days, single $(n=36)$ and twin-born $(\mathrm{n}=35)$, crossbreed lambs (Polwarth $x$ Finnish Landrace) were assigned to three feeding treatments (restriction period) in order to achieve: low weight gain (less than $30 \mathrm{~g} / \mathrm{lamb} /$ day; LWG), medium weight gain $(\sim 60 \mathrm{~g} / \mathrm{lamb} /$ day; MWG), and high weight gain $(\sim 90 \mathrm{~g} / \mathrm{lamb} /$ day; HWG) for 82 days. The Australian Graz Feed software (Graz Feed $\left.{ }^{\mathrm{TM}}, 2010\right)$ was used. Lambs at LWG were offered haylage from Lotus uliginosus cv. E-Tanin (596 g DM kg-1 $194 \mathrm{~g} \mathrm{CP} \mathrm{kg}^{-1} \mathrm{DM}$, and 2.31 Mcal ME kg-1 DM), haylage plus corn (623 $\mathrm{g} \mathrm{DM} \mathrm{kg}^{-1}, 182 \mathrm{~g} \mathrm{CP} \mathrm{kg}^{-1} \mathrm{DM}$, and $2.41 \mathrm{Mcal} \mathrm{ME}$ $\mathrm{kg}^{-1} \mathrm{DM}$ ) at MWG, and haylage plus corn and soybean meal (644 g DM kg-1 $185 \mathrm{~g} \mathrm{CP} \mathrm{kg}^{-1} \mathrm{DM}$, and $2.46 \mathrm{Mcal} \mathrm{ME} \mathrm{kg}^{-1} \mathrm{DM}$ ) at HWG. The feed was restricted between 2.5 to $3 \mathrm{~kg}$ of DM per 100 $\mathrm{kg}$ of live weight (LW) to maintain the average daily gain in each treatment. During the feeding restriction period, lambs of each treatment were collectively fed in uncovered collective pens, with an area of $30 \mathrm{~m}^{2} /$ lamb.

Subsequently, lambs were individually penned during the refeeding phase and fed ad libitum for 82 days with haylage (492 $\mathrm{g} \mathrm{DM} \mathrm{kg}^{-1}$, $165 \mathrm{~g} \mathrm{CP} \mathrm{kg}^{-1} \mathrm{DM}$, and $2.24 \mathrm{Mcal} \mathrm{ME} \mathrm{kg}{ }^{-1} \mathrm{DM}$ ). The pens had an area of $5 \mathrm{~m}^{2}$ each. Lambs in both experimental phases had fresh water and shade available ad libitum.

\section{Lamb measurements}

Lambs were weighed (LW) in a crate with a scale (Allflex, FX 11, Dallas, Texas, USA) on a biweekly basis at 08:00 am without fasting; average daily gain (ADG) was estimated for the restricted and not restricted phases. Feed intake (FI) was recorded daily during both experimental periods (restriction and ad libitum refeeding). Feed conversion ratio (FCR) was calculated as $\mathrm{kg}$ of feed per $\mathrm{kg}$ of weight gain for both periods.

Ribeye area (REA) and fat depth (FAT) were measured by ultrasound at the beginning and end of the refeeding phase. Measurements were taken using an Aloka SSD-500V real-time scanner (Aloka Co. Ltd., Tokyo, Japan) equipped with 12 $\mathrm{cm}, 3.5 \mathrm{MHz}$ linear probe set over the Longissimus dorsi muscle between the $12^{\text {th }}$ and $13^{\text {th }}$ ribs. Before each measurement, lamb's wool was brushed, and vegetable oil was used as a coupling medium between the skin and the probe.

\section{Statistical analysis}

Response variables during the feeding restriction period were analyzed as a $3 \times 2$ factorial design with treatment (LWR, MWR, or HWR) and litter size (single or twin) as fixed effects and the random effect of replicate using the PROC MIXED procedure of the Statistical Analysis System software (SAS Institute, 2013). Lamb LW was analyzed as repeated measures and the autoregressive (AR [1]) covariance structure was used based on the Akaike Information Criterion (Akaike, 1973). Birth weight was used as a covariate for LW, REA and FAT analysis. The refeeding phase was analyzed in the same way as the feeding restriction period (considered as previous treatments). Studentized residual plots were evaluated to test homogeneity of variance and normality for all data. Kenward-Roger approximation was used to calculate denominator degrees of freedom for different covariance structures for adjustment of the F-statistic. After the Analysis of Variance was performed, least square means were calculated for treatment comparisons with a significance level of $\alpha=0.05$, using the PDIFF option of LSMEANS, when F-tests were significant $(P<0.05)$. 


\section{RESULTS}

As expected, feeding restriction treatments had an effect $(P<0.05)$ on ADG (HWG $>$ MWG $>$ LWG $)$ and lambs achieved different $(P<0.05)$ weights at the end of the restriction period (Table $1)$. Feed intake was different $(P<0.05)$ among nutritional restriction treatments, showing the same pattern than ADG (Table 1). However, when FI was calculated as a percentage of BW or as percentage of metabolic $\mathrm{BW}$, no differences $(P$ $>0.05$ ) were found. Feed conversion ratio did not differ $(P>0.05)$ between MWG and HWG, but it was lower $(P<0.05)$ than LWG.

In the ad libitum refeeding phase with haylage, ADG did not differ $(P>0.05)$ among previous feeding treatments. No differences $(P>0.05)$ were found in ADG between single and twin-

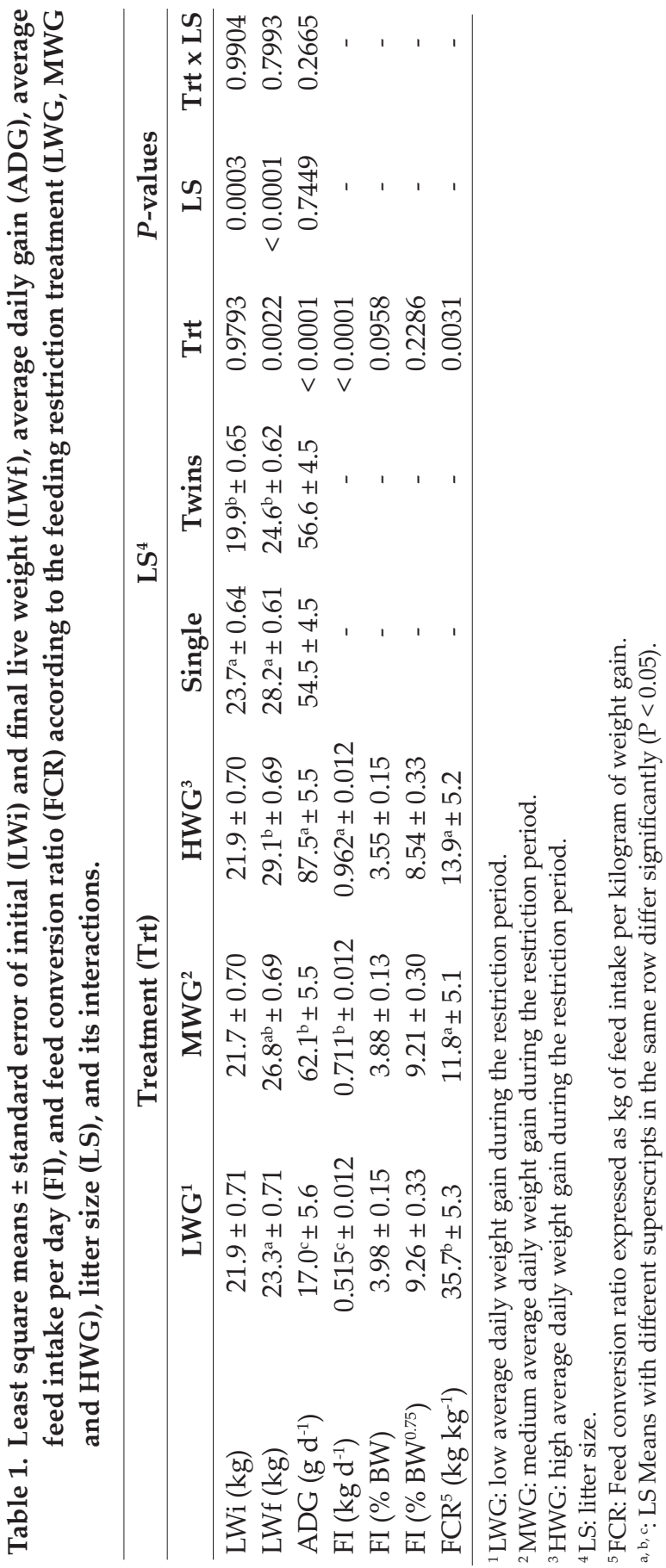


born lambs during the refeeding period (Table $2)$. Initial REA in the refeeding phase was greater $(P<0.05)$ in MWG and HWG lambs compared to the LWG treatment as a consequence of the dietary restriction period. These differences $(P<$ 0.05 ) were still present at the end of the refeeding phase, indicating that there was a carryover effect that was not overcome when lambs were fed ad libitum with haylage (Table 2). Lambs feed intake as a percentage of the metabolic weight was not different $(P>0.05)$ during the refeeding period with haylage among previous nutritional treatments. However, twin-born lambs showed a greater FI $(P<0.05)$ than single lambs, which

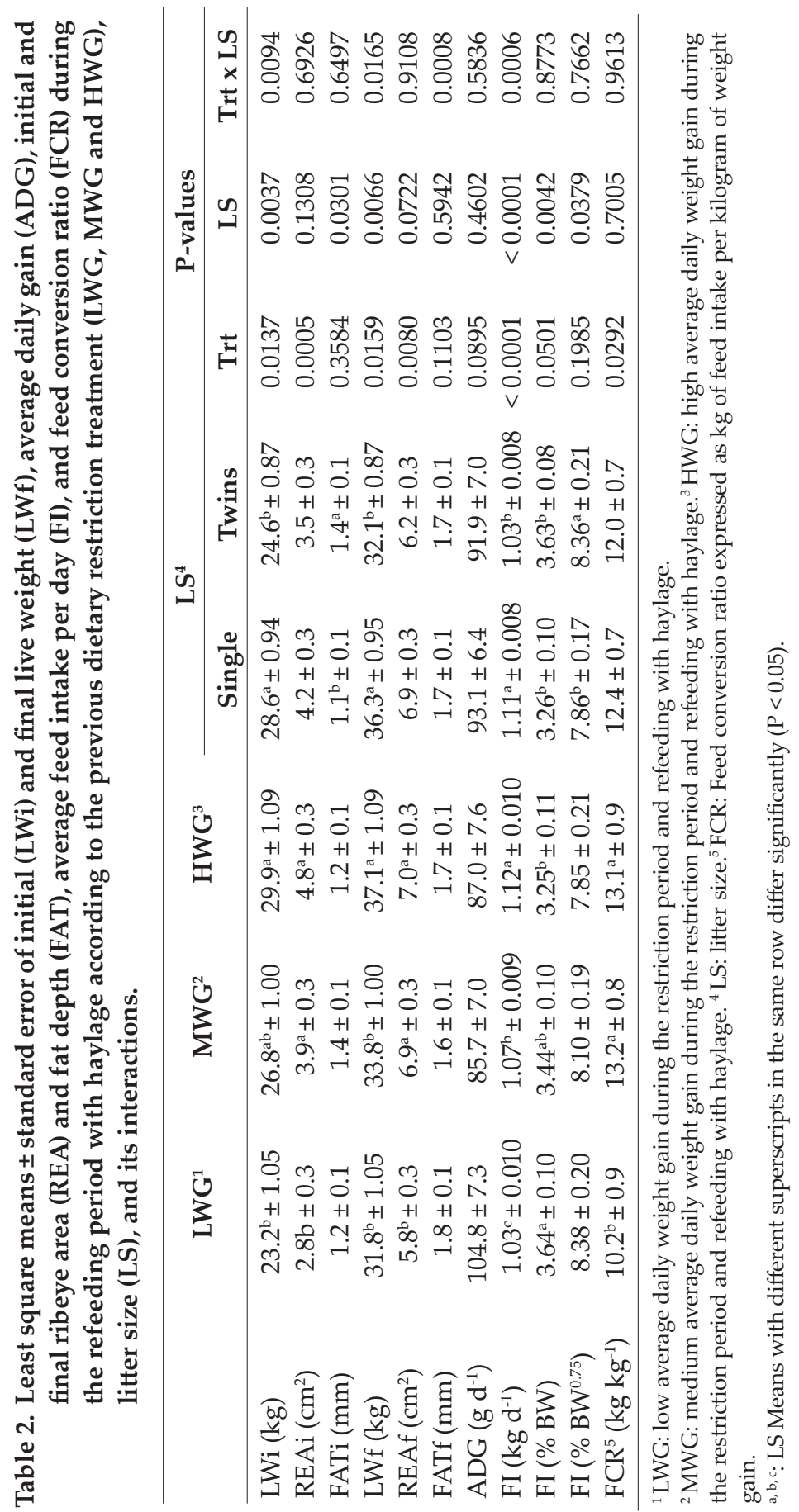


is associated to their metabolic weight (Table 2). Lambs from the previous LWG treatment presented a lower $(P<0.05)$ FCR (more efficient) than values from MWG and HWG during the refeeding period.

\section{DISCUSSION}

When animals undergo compensatory growth is indicative that growth rate is usually below the potential maximum. Compensatory growth is based on the existence of feedback mechanisms that lead to the induction of appropriate responses for the animal to meet certain growthrelated targets (Jobling, 2010). Even though dietary treatments determined significant differences in ADG during the restriction period, the magnitude of these differences, particularly between MWG and HWG, does not seem to be too big from a productive perspective. In this sense, and considering that the goal of this study was to evaluate compensatory growth, more contrasting nutritional treatments would have been necessary during the restriction phase. Sivanagendra Babu et al. (2017) indicated that the requirements for maintaining body weight are not a constant function of body weight but may be altered by plane of nutrition. In this study, ADG during the refeeding period did not differ among treatments. Similarly, a study conducted by Mahouachi and Atti (2005) did not find differences in ADG among the treatments during the refeeding phase when lambs presented an ADG of 61, 76 and $108 \mathrm{~g} \mathrm{~d}^{-1}$ in the previous restricted treatments. However, Li et al. (2015) reported that restricted lambs reduced markedly the weight of the rumen and abomasum; therefore, energy expenditure of these tissues could also decrease, which enabled more metabolic energy ingested by restricted lambs to be used for weight gain during the refeeding stage. In addition, Kamalzadeh et al. (1998) indicated that restriction affected carcass earlier than non-carcass components, while under nutrient restriction, the weight of highly metabolically active organs (gastrointestinal tract, liver and heart) as proportions of body weight are affected to a lesser extent than body weight.

No differences were found in terms of FI as a percentage of metabolic weight, indicating that animals consumed the same proportion of feed during the restriction period. However, LWG lambs presented a greater FCR, which indicates less efficiency converting feed to weight gain. This agrees with the findings of Greeff et al. (1986), who reported a dramatic decrease in feed utilization in lambs with an ADG of $30 \mathrm{~g} \mathrm{~d}^{-1}$. Reduction of growth rate in restricted animals may be due to the influence of the plane of nutrition on feed utilization efficiency and the amount of feed required for maintenance (Sivanagendra Babu et al., 2017). During the feed restriction phase, Abouheif et al. (2013) also reported that feed efficiency decreased as the level of restriction increased.

Thomson et al. (1982) found that although underfed animals took longer to reach slaughter weight, their total intake of gross energy and overall energy conversion ratio (considering restricted feeding and refeeding phases) were similar to those under non-restricted feeding conditions. However, the overall feed conversion ratio in our study was greater (less efficient) in LWG lambs.

The increase of feed intake during the compensatory growth seems to be driven by meeting protein requirements. Sheep have the capacity to select their diets to maximize growth (Kyriazakis and Oldham, 1993), but probably protein intake during the refeeding phase was not enough to promote compensatory growth. Addah et al. (2017) reported that refeeding of protein was more effective at inducing compensatory growth compared to energy intake. However, even if the magnitude of compensation is proportional to the intensity of the previous growth restriction, the response varies largely (Hornick et al., 2000). In this study, LW differences between LWG and HWG were $6.7 \mathrm{~kg}$ at the beginning and $5.3 \mathrm{~kg}$ at the end of the refeeding phase, which indicates a partial compensation (Jobling, 2010).

\section{CONCLUSIONS}

Even though haylage is a cheap feed alternative in semi-extensive lamb production systems, it does not enable a full compensatory growth of LWG and MWG lambs. It seems that a minimum ADG of $90 \mathrm{~g} \mathrm{a}^{-1} \mathrm{~d}^{-1}$ in the summer is necessary to achieve (in the fall) the minimum weight ( $34 \mathrm{~kg}$ ) required to qualify for the Uruguayan heavy lamb program, particularly when refeeding conditions may limit compensatory growth.

\section{LITERATURE CITED}

Abouheif, M., A. Al-Owaimer, M. Kraidees, H. Metwally, and T. Shafey. 2013. Effect of restricted feeding and realimentation on feed performance and carcass characteristics of growing lambs. Revista Brasileira de Zootecnia 42(2):95-101.

Addah, W., A. Ayantunde, and E.K. Okine. 2017. Effects of restricted feeding and realimentation of dietary protein or energy on compensatory growth sheep. South African Journal of Animal Science 47(3):389-398. 
Akaike, H. 1973. Information theory as an extension of the maximum likelihood principle. p. 267-281. In B.N. Petrov and F. Csaki (eds.) Second International Symposium on Information Theory. Akademiai Kiado, Budapest.

Bermúdez, R., and W. Ayala. 2005. Producción de forraje de un campo natural de la zona de lomadas del Este. In R. Gómez Miller and M.M. Albicette (eds.) Seminario de Actualización Técnica en Manejo de Campo Natural. Serie Técnica № 151. p. 33-39. National Institute for Agricultural Research, Montevideo, Uruguay. Disponible en http://www. inia.uy/Publicaciones/Documentos \%20 compartidos/15630021107142110.pdf (Consulta agosto 31 2018)

Berretta, E.J., D. Risso, F. Montossi, and G. Pigurina. 2000. Campos in Uruguay. In G. Lemaire, J. Hodgson, A. de Moraes, P.C. d. F. Carvalho, C. Nabinger (eds.) Grassland ecophysiology and grazing ecology. Cab International. p. 377-394. University Press, Cambridge, UK.

Butler-Hogg, B.W., and N.M. Tulloh. 1982. Growth patterns in sheep: the effects of weight losses on compensatory growth and feed intake in Corriedale sheep. The Journal of Agricultural Science 99:641-649.

Castells D., V. Gayo, A. Mederos, D. Martínez, E. Risso, A. Rodríguez, et al. 2011. Epidemiological study of gastro-intestinal nematodes of sheep in Uruguay: Prevalence and seasonal dynamics. In Proceedings $23^{\text {rd }}$ International Conference of the World Association for the Advancement of Veterinary Parasitology. Buenos Aires Argentina.

Connor, E.E., S. Kahl, T.H. Elsasser, J.S. Parker, R.W. Li, C.P. Van Tassell, et al. 2010. Enhanced mitochondrial complex gene function and reduced liver size may mediate improved feed efficiency of beef cattle during compensatory growth. Functional \& Integrative Genomics 10:39-51. doi 10.1007/ s10142-009-0138-7

Fox, D.G., R.R Johnson, R.L. Preston, T.R. Dockerty, and E.W. Klosterman. 1972. Protein and energy utilization during compensatory growth in beef cattle. Journal of Animal Science 34:310-318.

Graham, N.M., and T.W. Searle. 1979. Studies of weaned lambs before, during and after a period of weight loss. I. Energy and nitrogen utilization. Australian Journal of Agricultural Research 30(3):513-523.
GrazFeed $^{\mathrm{TM}}$ 2010. Version 5.03. CSIRO. Horizon Agriculture. NSW, Australia. Available at http://www.hzn.com.au/grazfeed.php (Accessed 8 March 2019).

Greeff, J.C., H.H. Meissner, C.Z. Roux, and R.J. Janse van Rensburg. 1986. The effect of compensatory growth on feed intake, growth rate and efficiency of feed utilization in sheep. South African Journal of Animal Science 16(4):155-161.

Hector, K.L., and S. Nakagawa. 2012. Quantitative analysis of compensatory and catch-up growth in diverse taxa. Journal of Animal Ecology 81:583-593. doi: 10.1111/j.13652656.2011.01942.x.

Hornick, J.L., C. Van Eenaeme, A. Clinquart, M. Diez, and L. Istasse. 1998. Different periods of feed restriction before compensatory growth in Belgian Blue bulls: I. Animal performance, nitrogen balance, meat characteristics, and fat composition. Journal of Animal Science 76(1):249-259.

Hornick, J.L., C. Van Eenaeme, O. Gérard, I. Dufrasne, and L. Istasse. 2000. Mechanisms of reduced and compensatory growth. Domestic Animal Endocrinology 19:121-132.

Jobling, M. 2010. Are compensatory growth and catch-up growth two sides of the same coin? Aquaculture International 18:501-510. doi 10.1007/s10499-009-9260-8

Kamalzadeh, A., W.J. Koops, J. van Bruchem, S. Tamminga, and D. Zwart. 1998. Feed quality restriction and compensatory growth in growing sheep: development of body organs. Small Ruminant Research 29:71-82.

Keogh, K., S.M. Waters, A.K. Kelly, and D.A. Kenny. 2015a. Feed restriction and subsequent realimentation in Holstein Friesian bulls: I. Effect on animal performance, muscle, fat, and linear body measurements; and slaughter characteristics. Journal of Animal Science. 93: 3578-3589. doi:10.2527/jas20148470

Keogh, K., D.A. Kenny, A.K. Kelly, and S.M. Waters. 2015b. Insulin secretion and signaling in response to dietary restriction and subsequent re-alimentation in cattle. Physiological Genomics 47:344-354. doi:10.1152/physiolgenomics.00002.2015.

Kyriazakis, I., and J.D. Oldham. 1993. Diet selection in sheep: the ability of growing lambs to select a diet that meets their crude protein (nitrogen $x$ 6.25) requirements. British Journal of Nutrition 69:617-629.

Levy, D., Y. Folman, Z. Holzer, and D. Drori. 1971. Compensatory growth in intensively raised bull calves. Journal of Animal Science 33(5):1078-1085. 
Li, D.B., X.G. Liu, C.Z. Zhang, G.L. Kao, and X.Z. Hou. 2015. Effects of nutrient restriction followed by realimentation on growth, visceral organ mass, cellularity, and jejunal morphology in lambs. Livestock Science 173:24-31. doi.org/10.1016/j.livsci.2014.12.011

Mahouachi, M., and N. Atti. 2005. Effects of restricted feeding and re-feeding of Barbarine lambs: intake, growth and non-carcass components. Animal Science 81(2):305-312.

Mc Gregor, E.M., C.P. Campbell, S.P. Miller, P.P. Purslow, and I.B. Mandell. 2012. Effect of nutritional regimen including limit feeding and breed on growth performance, carcass characteristics and meat quality in beef quality. Canadian Journal of Animal Science 92: 327-341. doi:10.4141/CJAS2011-126

Mitchell, A.D. 2009. Effect of ractopamine on growth and body composition of pigs during compensatory growth. Animal 3(1):173-180. doi:10.1017/S1751731108003285

Ryan, W.J. 1990. Compensatory growth in cattle and sheep. Nutrition Abstracts and Reviews. Series B, Livestock Feeds and Feeding 60(9):653-664.
Sainz, R.D., F. De la Torre, and J.W. Oltjen. 1995. Compensatory growth and carcass quality in growth-restricted and refed beef steers. Journal of Animal Science 73:2971-2979.

SAS Institute Inc. 2013. SAS® 9.4. SAS Institute, Cary, NC, USA.

Sivanagendra Babu, B., M.V.A.N. Suryanarayana, E. Raghava Rao, and P. Asha Latha. 2017. Effect of feed restriction on serum biochemical profile and carcass characteristics in ram lambs. International Journal of Current Microbiology and Applied Sciences 6(9):566-572. doi: https://doi.org/10.20546/ ijcmas.2017.609.068

Thomson, E.F., H. Bickel, and A. Schurch. 1982. Growth performance and metabolic in lambs and steers after mild nutritional restriction. The Journal of Agricultural Science 98:183194. doi.org/10.1017/S0021859600041277 